\title{
To the Problem of Hygienic efficiency of LED lighting Facilities
}

\author{
Olga Evgenyevna Zheleznikova ${ }^{1}$, Lyudmila Vasilyevna Sinitsyna ${ }^{1}$ \\ and Svetlana Anatolyevna Mikaeva ${ }^{2}$
}

\begin{abstract}
${ }^{1}$ Ogarev Mordovia State University, 68 Bolshevistskaya Str., Saransk 430005, Republic of Mordovia.
${ }^{2}$ Moscow state University of instrument engineering and Informatics, 20 Stromynka str., Moscow 107996, Russia.
\end{abstract}

DOI: http://dx.doi.org/10.13005/bbra/1913

(Received: 25 September 2015; accepted: 30 October 2015)

\begin{abstract}
The object of the paper is experimental investigation of LED lighting hygienic efficiency. A comprehensive methodology for psychophysiological and hygienic assessment of the LED lighting equipment which (the methodology) was elaborated by the authors was used in the course of the experiments. The experiments were carried out by means of a designed experimental research facility ensuring variation of luminescent (basic) and LED lighting. There were selected the indicators of the visual organ state which are the most optimal and complying with the investigational tasks. The article describes the most significant results of the experimental investigations. A practical relevance of the received experimental material used for LED lighting was demonstrated.
\end{abstract}

Key words: light-emitting diodes (LEDs), lighting, integrated methodology, experimental research facility, visual functions, visual fatigue, psychophysiological image.

One of the important tasks of the light engineering is creation of a favorable light-andcolor environment suggesting use of light for satisfaction of a range of the human needs: ergonomic, psychophysiological, psychological and ecological. On the other hand the problems of saving energy consumed for lighting purposes are as well of current concern. It is possible to solve the mentioned problems by means of use of LEDs which are considered to be the most effective and challenging light sources (LSs) nowadays.

However, if energy saving in the lighting equipment due to use of LEDs and high luminous efficiency of the same is quite obvious (Kawasaki et al., 2012; Aladov A.V. et al., 2010; Borovkov S.A., 2011; Radomsky N.V., 2012; Eliseyev N.P. Reshenov S.P., 2012; Wittig N., 2012; Hirayama, H. 2014) the possibility of LEDs use for ensuring

\footnotetext{
* To whom all correspondence should be addressed. E-mail:mikaeva@npo.lit.ru
}

comfortable lighting conditions requires a convincing evidence that can be obtained by comprehensive studies of the effect of LED lighting on the visual organ and the body as a whole. The Russian and foreign scientists in their works mention certain results of studying the effect of LED lighting on the visual functions and visual performance. The results of the said investigations are contradictory and ambiguous (Aladov, A.V. et al., 2012; Zak, P.P., Ostrovsky A.A., 2012; Bizjak G. et al., 2013; Wright M., 2010; Kuchma V.R. et al, 2013; Behar-Cohen T et al., 2011; Zakgeim A.L., 2012; Teksheva L.M., 2012; Sliney D.H., 2010; Düe D., 2012). It gives ground to considerations that the experimental investigations aimed at hygienic and psychophysiological evaluation of LED lighting would have importance.

Methodology

Taking into account the theoretical and experimental material covering the effect of factors relating to the lighting conditions on visual performance and fatigue we have elaborated a comprehensive methodology for 
psychophysiologic and hygienic evaluation of the LED lighting equipment (Amelkina et. al., 2013). In this sense the investigations of the visual organ functional state and of visual fatigue progression under the LED lighting conditions were of specific concern since the rated features of the lighting equipment are primarily connected with the visual functions. Given the nature of the visual activity we have chosen the most responsive indicators of the visual organ state:

a) absolute accommodation extent and time of achromatic asthenopia (accommodativemuscular system);

b) distance visual acuity, projected blind spot area, chromatic vision acuity (receptor system);

c) critical flicker fusion frequency (CFFF) (central division).

The integral evaluation of LED lighting efficiency was carried out on the basis of the visual fatigue indicator measured after completion of visual activity:

$$
\text { A } 1 \frac{t_{j}}{t_{i}} \quad 100 \%
$$

where

$t_{j}$ - time of achromatic asthenopia after activity completion;

$t_{i}$ - time of achromatic asthenopia before activity start.

For the purpose of investigations, there was designed and installed a general-lighting experimental research facility (ERF) ensuring LED lighting and luminescent lamp lighting variants realization. The variants with LL lighting are regarded as basic when compared with LED lighting. The investigations were performed at various illumination intensity levels: 200, 400 and $1000 \mathrm{~lx}$ and various correlated color temperature values (Tc) of the illumination sources: 3000, 4000 and $5000 \mathrm{~K}$.

\section{RESULTS}

A group of volunteer students aged between 20 and 25 years who passed a preliminary clinical examination took part in the experiments. The clinical examination of the visual organ included measurement of refraction and vision acuity; computer-aided tomography of the retina. All of the enrolled observers had predominantly emmetropic refraction, acuity of vision for the both eyes - 1.0; no abnormalities in color perception. The enrolled observers totaling to 60 persons were randomized into two panels each containing 30 of them: a reference panel which participated in the experiment being subject to luminescent lamp (LL) lighting and a primary panel which was subject to

$t \cdot q_{\bar{x}} \mathrm{ED}$ lighting. The number of observers and the number of experiments was determined based on the requirements to obtain statistically reliable data. Work schedules for the observers were made up. Each observer took part in the experiment at the same time with regard to their daily biorhythms. The experiment was carried out twice a day: from 9.00 a.m. to $12.00 \mathrm{a} . \mathrm{m}$. and from 4.00 p.m. to 7.00 p.m. In accordance with work schedule man-hours

Table 1. Change of absolute accommodation extent after visual workload under LED lighting conditions

\begin{tabular}{|c|c|c|c|c|c|c|c|}
\hline \multirow{2}{*}{$\begin{array}{l}\text { Illumina-tion } \\
\text { intensity, lx }\end{array}$} & \multirow[t]{2}{*}{ Tc, K } & \multicolumn{2}{|c|}{ Before activity } & \multicolumn{2}{|c|}{ After activity } & \multicolumn{2}{|c|}{ Correlation index } \\
\hline & & $\begin{array}{c}\text { AAE, } \\
\text { diopter, } \\
\bar{x}\end{array}$ & $\begin{array}{l}\text { confidence } \\
\text { interval, }\end{array}$ & $\begin{array}{l}\text { AAE, } \\
\text { diopter } \\
\bar{x}\end{array}$ & $\begin{array}{l}\text { confidence } \\
\text { interval, }\end{array}$ & $\begin{array}{c}\text { r (between } \\
\text { before and } \\
\text { after activity) }\end{array}$ & $\mathrm{p}(\mathrm{r})$ \\
\hline 200 & 3000 & 8.7 & 0.096 & 8.4 & 0.214 & 0.7458 & $\mathrm{p}<0.05$ \\
\hline 400 & & 9.0 & 0.208 & 8.8 & 0.120 & 0.8505 & $\mathrm{p}<0,01$ \\
\hline 1000 & & 9.9 & 0.157 & 9.7 & 0.186 & 0.7261 & $\mathrm{p}<0.05$ \\
\hline 200 & 4000 & 9.4 & 0.133 & 9.0 & 0.115 & 0.6749 & $\mathrm{p}<0.05$ \\
\hline 400 & & 9.7 & 0.168 & 9.5 & 0.188 & 0.6536 & $\mathrm{p}<0.05$ \\
\hline 1000 & & 10.1 & 0.132 & 10.2 & 0.179 & 0.1433 & - \\
\hline 200 & 5000 & 9.3 & 0.107 & 8.7 & 0.147 & 0.7932 & $\mathrm{p}<0.05$ \\
\hline 400 & & 9.7 & 0.133 & 9.4 & 0.176 & 0.6598 & $\mathrm{p}<0.05$ \\
\hline 1000 & & 10.0 & 0.221 & 9.8 & 0.243 & 0.6272 & $\mathrm{p}<0.05$ \\
\hline
\end{tabular}


in LED lighting conditions made 488, and in fluorescent lighting conditions with regard to earlier results -522 .
Before the investigations start the observers had a research techniques training course until obtaining stable results. After that a

Table 2. Change of absolute accommodation extent after visual workload under fluorescent lighting conditions

\begin{tabular}{|c|c|c|c|c|c|c|c|}
\hline \multirow{2}{*}{$\begin{array}{l}\text { Illumina-tion } \\
\text { intensity, lx }\end{array}$} & \multirow[t]{2}{*}{ Tc, K } & \multicolumn{2}{|c|}{ Before activity } & \multicolumn{2}{|c|}{ After activity } & \multicolumn{2}{|c|}{ Correlation index } \\
\hline & & $\begin{array}{l}\text { AAE, } \\
\text { diopter, } \\
\bar{x}\end{array}$ & $\begin{array}{l}\text { confidence } \\
\text { interval, }\end{array}$ & $\begin{array}{l}\text { AAE, } \\
\text { diopter } \\
\qquad \bar{x}\end{array}$ & $\begin{array}{l}\text { confidence } \\
\text { interval, }\end{array}$ & $\begin{array}{l}\text { r (between } \\
\text { before and } \\
\text { after activity) }\end{array}$ & $\mathrm{p}(\mathrm{r})$ \\
\hline 200 & 3000 & 8.6 & 0.207 & 8.2 & 0.124 & 0,7287 & $\mathrm{p}<0.01$ \\
\hline 400 & & 8.8 & 0.200 & 8.6 & 0.101 & 0,6942 & $\mathrm{p}<0.05$ \\
\hline 1000 & & 9.6 & 0.135 & 9.4 & 0.103 & 0,7362 & $\mathrm{p}<0.01$ \\
\hline 200 & 4000 & 8.8 & 0.139 & 8.3 & 0.158 & 0,6872 & $\mathrm{p}<0.05$ \\
\hline 400 & & 9.1 & 0.145 & 8.8 & 0.101 & 0,7667 & $\mathrm{p}<0.01$ \\
\hline 1000 & & 9.8 & 0.141 & 9.6 & 0.116 & 0.8513 & $\mathrm{p}<0.001$ \\
\hline 200 & 5000 & 8.7 & 0.295 & 8.2 & 0.266 & 0.6345 & $\mathrm{p}<0.05$ \\
\hline 400 & & 9.1 & 0.170 & 8.7 & 0.228 & 0.8301 & $\mathrm{p}<0.001$ \\
\hline 1000 & & 9.7 & 0.100 & 9.4 & 0.075 & 0.7175 & $\mathrm{p}<0.05$ \\
\hline
\end{tabular}

Table 3. AAE change significance after visual workload under researched lighting variants

\begin{tabular}{llll}
\hline $\begin{array}{l}\text { Illumination } \\
\text { intensity, lx }\end{array}$ & Tc, K & Compared lighting variants & $\begin{array}{c}\text { Change significance according to } \\
\text { the Student's t-test }\end{array}$ \\
\hline 200 & 3000 & LED lighting-fluorescent lighting \\
400 & & LED lighting- & - \\
1000 & & fluorescent lighting & - \\
200 & 4000 & LED lighting-fluorescent lighting & $<0.05$ \\
400 & & & $<0.05$ \\
1000 & 5000 & & $<0.05$ \\
200 & & $<0.05$ \\
400 & & - \\
1000 & & $<$ \\
\hline
\end{tabular}

Table 4. AA time threshold change after visual workload under different LED lighting variants

\begin{tabular}{|c|c|c|c|c|c|c|c|}
\hline \multirow{2}{*}{$\begin{array}{l}\text { Illumina-tion } \\
\text { intensity, lx }\end{array}$} & \multirow[t]{2}{*}{ Tc, K } & \multicolumn{2}{|c|}{ Before activity } & \multicolumn{2}{|c|}{ After activity } & \multicolumn{2}{|c|}{ Correlation index } \\
\hline & & $\begin{array}{c}\text { AAE, } \\
\text { diopter, } \\
\bar{x}\end{array}$ & $\begin{array}{l}\text { confidence } \\
\text { interval, }\end{array}$ & $\begin{array}{l}\text { AAE, } \\
\text { diopter } \\
\bar{x}\end{array}$ & $\begin{array}{l}\text { confidence } \\
\text { interval, }\end{array}$ & $\begin{array}{l}\text { r (between } \\
\text { before and } \\
\text { after activity) }\end{array}$ & $\mathrm{p}(\mathrm{r})$ \\
\hline 200 & 3000 & 11.2 & 0.1875 & 9.5 & 0.1739 & 0.6821 & $\mathrm{p}<0.05$ \\
\hline 400 & & 11.5 & 0.1634 & 10.1 & 0.2003 & 0.5449 & $\mathrm{p}<0.05$ \\
\hline 1000 & & 12.4 & 0.1811 & 11.6 & 0.1752 & 0.6216 & $\mathrm{p}<0.05$ \\
\hline 200 & 4000 & 11.4 & 0.1309 & 9.7 & 0.1101 & 0.7563 & $\mathrm{p}<0.01$ \\
\hline 400 & & 11.6 & 0.2224 & 10.3 & 0.1504 & 0.7218 & $\mathrm{p}<0.01$ \\
\hline 1000 & & 12.5 & 0.1646 & 11.7 & 0.1491 & 0.6414 & $\mathrm{p}<0.05$ \\
\hline 200 & 5000 & 11.3 & 0.2125 & 9.7 & 0.1525 & 0.7116 & $\mathrm{p}<0.05$ \\
\hline 400 & & 11.7 & 0.1949 & 10.3 & 0.1175 & 0.7116 & $\mathrm{p}<0.01$ \\
\hline 1000 & & 12.7 & 0.1380 & 11.6 & 0.1297 & 0.7378 & $\mathrm{p}<0.01$ \\
\hline
\end{tabular}


60-day-long series of laboratory experiments was carried out. After its completion the observers were repeatedly examined under clinical conditions in order to determine whether there was any negative effect of LED lighting on the visual organ. It worth mentioning that the physicians were not aware of the light sources used in the course of the observers' activity.

A laboratory experiment aimed at the study of LED lighting effect on the visual organ and the human body as a whole (as compared with fluorescent lighting) was conducted in laboratory \# 316 of the Lighting engineering faculty of the Ogarev Mordovia State University. The laboratory included 4 workspaces: the first of them was intended to be used for inspection (quantity measurement) of the observers' visual functions prior to start and after completion; the rest of them which were experimental, were meant for research under different lighting variants according to the schedule.

The experiment procedure for each lighting variant consisted of the following. In the first workspace the observers (2 people) were examined for distance visual acuity using Rot lamp. These measurements were not taken every day but twice a week and only before start of activity in order to control this visual function.

Then chromatic thresholds measurements were taken uniocularly for the both eyes by means of anomaloscope AN-59.

Then the observers entered one of experimental workspaces depending on the lighting variant under research - either using

Table 5. AA time threshold change after visual workload under different fluorescent lighting variants

\begin{tabular}{|c|c|c|c|c|c|c|c|}
\hline \multirow{2}{*}{$\begin{array}{l}\text { Illumina-tion } \\
\text { intensity, lx }\end{array}$} & \multirow[t]{2}{*}{ Tc, K } & \multicolumn{2}{|c|}{ Before activity } & \multicolumn{2}{|c|}{ After activity } & \multicolumn{2}{|c|}{ Correlation index } \\
\hline & & $\begin{array}{l}\text { AAE, } \\
\text { diopter, } \\
\bar{x}\end{array}$ & $\begin{array}{c}\text { confidence } \\
\text { interval, }\end{array}$ & $\begin{array}{l}\text { AAE, } \\
\text { diopter } \\
\bar{x}\end{array}$ & $\begin{array}{l}\text { confidence } \\
\text { interval, }\end{array}$ & $\begin{array}{l}\text { r (between } \\
\text { before and } \\
\text { after activity) }\end{array}$ & $\mathrm{p}(\mathrm{r})$ \\
\hline 200 & 3000 & 10.3 & 0.117 & $\bar{\sigma}_{\bar{x}} 8.2$ & 0.125 & 0.7812 & $\mathrm{p}<0.01$ \\
\hline 400 & & 10.4 & 0.267 & 8.5 & 0.206 & 0.7124 & $\mathrm{p}<0.05$ \\
\hline 1000 & & 11.4 & 0.253 & 9.5 & 0.187 & 0.6590 & $\mathrm{p}<0.05$ \\
\hline 200 & 4000 & 10.4 & 0.327 & 8.4 & 0.145 & 0.6377 & $\mathrm{p}<0.05$ \\
\hline 400 & & 10.5 & 0.118 & 8.7 & 0.139 & 0.6642 & $\mathrm{p}<0.05$ \\
\hline 1000 & & 11.7 & 0.223 & 10.6 & 0.199 & 0.7019 & $\mathrm{p}<0.05$ \\
\hline 200 & 5000 & 10.4 & 0.238 & 8.5 & 0.282 & 0.6981 & $\mathrm{p}<0.05$ \\
\hline 400 & & 10.5 & 0.166 & 8.7 & 0.160 & 0.4501 & $\mathrm{p}<0.05$ \\
\hline 1000 & & 11.5 & 0.297 & 10.4 & 0.218 & 0.5636 & $\mathrm{p}<0.05$ \\
\hline
\end{tabular}

Table 6. Evaluation of statistical correlation between light environment parameters and AA time threshold change after visual workload

\begin{tabular}{|c|c|c|c|c|c|}
\hline \multirow[t]{2}{*}{ Compared lighting variants } & \multirow[t]{2}{*}{ E, lx } & \multirow[t]{2}{*}{ Tc, K } & \multicolumn{3}{|c|}{$\begin{array}{c}\text { Statistical indicators in compared variants at } \\
\text { degrees of freedom } \mathrm{f}\end{array}$} \\
\hline & & & {$[\mathrm{hy}]^{2}$} & $\mathrm{p}$ & C. $10^{-2}$ \\
\hline \multirow[t]{3}{*}{ LED lighting -fluorescent lighting } & 200 & \multirow[t]{3}{*}{3000} & 4.53 & - & 1.07 \\
\hline & 400 & & 13.65 & $<0.05$ & 3.20 \\
\hline & 1000 & & 23.80 & $<0.001$ & 5.70 \\
\hline \multirow[t]{3}{*}{ LED lighting -fluorescent lighting } & 200 & \multirow[t]{3}{*}{4000} & 11.08 & $<0.01$ & 2.60 \\
\hline & 400 & & 52.92 & $<0.001$ & 8,80 \\
\hline & 1000 & & 24.86 & $<0.001$ & 4.10 \\
\hline \multirow[t]{3}{*}{ LED lighting -fluorescent lighting } & 200 & \multirow[t]{3}{*}{5000} & 6.65 & $<0.05$ & 2.11 \\
\hline & 400 & & 9.44 & $<0.05$ & 3.30 \\
\hline & 1000 & & 11.96 & $<0.05$ & 4.20 \\
\hline
\end{tabular}


fluorescent or LED light sources - to be tested for projected blind spot area uniocularly for both eyes by means of a campimeter.

After that the observers sat at a desk and were adjusting to studied lighting conditions for 15 minutes. Upon the researchers' command the observers were working with proof samples for 2 minutes. The next step was uniocular determination of the nearest distinct vision point for each eye followed by calculation of the absolute accommodation extent (AAE). Then binocular measurement of the time of achromatic asthenopia

Table 7. Computer-assisted tomography of the retina values of the observers in the reference panel

\begin{tabular}{lccc}
\hline Indicator & $1^{\text {st }}$ day & $60^{\text {th }}$ day & $\begin{array}{c}\text { Significance according } \\
\text { to the Student's t-test }\end{array}$ \\
& & & \\
\hline Foveola minimum, um & $165.4 \pm 6.2$ & $167.7 \pm 5.1$ & $\mathrm{p}>0.05$ \\
Foveola average thickness, um & $198.05 \pm 3.4$ & $200.9 \pm 4.5$ & $\mathrm{p}>0.05$ \\
Foveola volume, mm ${ }^{3}$ & $0.15 \pm 0.003$ & $0.15 \pm 0.003$ & $\mathrm{p}>0.05$ \\
Macula volume, mm ${ }^{3}$ & $6.7 \pm 0.05$ & $6.7 \pm 0.04$ & $\mathrm{p}>0.05$ \\
Macula internal temporal sector, um & $259.7 \pm 2.5$ & $259.8 \pm 2.6$ & $\mathrm{p}>0.05$ \\
Macula internal upper sector, um & $270.9 \pm 2.4$ & $270.9 \pm 2.5$ & $\mathrm{p}>0.05$ \\
Macula internal nose sector, um & $270.05 \pm 2.3$ & $269.8 \pm 2.7$ & $\mathrm{p}>0.05$ \\
Macula internal lower sector, um & $268.9 \pm 2.6$ & $269.6 \pm 2.5$ & $\mathrm{p}>0.05$ \\
Macula external temporal sector, um & $219.9 \pm 2.7$ & $220.6 \pm 2.7$ & $\mathrm{p}>0.05$ \\
Macula external upper sector, um & $228.0 \pm 1.8$ & $229.0 \pm 2.1$ & $\mathrm{p}>0.05$ \\
Macula external nose sector, um & $240.4 \pm 2.4$ & $246.4 \pm 3.2$ & $\mathrm{p}>0.05$ \\
Macula external lower sector, um & $219.8 \pm 2.5$ & $212.3 \pm 3.4$ & $\mathrm{p}>0.05$ \\
Optic disc area, mm ${ }^{2}$ & $2.1 \pm 0.06$ & $2.2 \pm 0.04$ & $\mathrm{p}>0.05$ \\
Disc rim volume, mm ${ }^{3}$ & $0.5 \pm 0.05$ & $0.6 \pm 0.04$ & $\mathrm{p}>0.05$ \\
Disc rim area, mm ${ }^{2}$ & $1.6 \pm 0.07$ & $1.7 \pm 0.05$ & $\mathrm{p}>0.05$ \\
Excavation area, mm ${ }^{2}$ & $0.5 \pm 0.06$ & $0.4 \pm 0.05$ & $\mathrm{p}>0.05$ \\
Excavation volume, mm ${ }^{3}$ & $0.08 \pm 0.02$ & $0.07 \pm 0.02$ & $\mathrm{p}>0.05$ \\
Ratio of area to excavation & $0.24 \pm 0.02$ & $0.29 \pm 0.02$ & $\mathrm{p}>0.05$ \\
\hline
\end{tabular}

Table 8. Computer-assisted tomography of the retina values of the observers in the primary panel

\begin{tabular}{lccc}
\hline Indicator & $1^{\text {st }}$ day & $60^{\text {th }}$ day & $\begin{array}{c}\text { Significance according } \\
\text { to the Student's t-test }\end{array}$ \\
& & & \\
\hline Foveola minimum, um & $165.6 \pm 5.2$ & $166.9 \pm 5.4$ & $\mathrm{p}>0.05$ \\
Foveola average thickness, um & $199.05 \pm 3.7$ & $200.2 \pm 4.2$ & $\mathrm{p}>0.05$ \\
Foveola volume, mm ${ }^{3}$ & $0.15 \pm 0.003$ & $0.15 \pm 0.003$ & $\mathrm{p}>0.05$ \\
Macula volume, mm ${ }^{3}$ & $6.7 \pm 0.05$ & $6.7 \pm 0.05$ & $\mathrm{p}>0.05$ \\
Macula internal temporal sector, um & $259.8 \pm 2.3$ & $259.9 \pm 2.5$ & $\mathrm{p}>0.05$ \\
Macula internal upper sector, um & $270.9 \pm 2.3$ & $270.9 \pm 2.5$ & $\mathrm{p}>0.05$ \\
Macula internal nose sector, um & $270.05 \pm 2.4$ & $269.8 \pm 2.6$ & $\mathrm{p}>0.05$ \\
Macula internal lower sector, um & $268.8 \pm 2.5$ & $269.5 \pm 2.7$ & $\mathrm{p}>0.05$ \\
Macula external temporal sector, um & $219.5 \pm 2.4$ & $220.4 \pm 2.8$ & $\mathrm{p}>0.05$ \\
Macula external upper sector, um & $228.0 \pm 1.6$ & $230.0 \pm 2.0$ & $\mathrm{p}>0.05$ \\
Macula external nose sector, um & $239.7 \pm 2.5$ & $247.3 \pm 3.6$ & $\mathrm{p}>0.05$ \\
Macula external lower sector, um & $219.5 \pm 2.6$ & $212.2 \pm 3.6$ & $\mathrm{p}>0.05$ \\
Optic disc area, mm ${ }^{2}$ & $2.1 \pm 0.04$ & $2.2 \pm 0.05$ & $\mathrm{p}>0.05$ \\
Disc rim volume, mm ${ }^{3}$ & $0.5 \pm 0.04$ & $0.6 \pm 0.05$ & $\mathrm{p}>0.05$ \\
Disc rim area, mm ${ }^{2}$ & $1.6 \pm 0.06$ & $1.7 \pm 0.06$ & $\mathrm{p}>0.05$ \\
Excavation area, mm ${ }^{2}$ & $0.5 \pm 0.05$ & $0.4 \pm 0.05$ & $\mathrm{p}>0.05$ \\
Excavation volume, mm ${ }^{3}$ & $0.08 \pm 0.01$ & $0.06 \pm 0.02$ & $\mathrm{p}>0.05$ \\
Ratio of area to excavation & $0.23 \pm 0.02$ & $0.28 \pm 0.02$ & $\mathrm{p}>0.05$ \\
& & & \\
\hline
\end{tabular}


Table 9. Visual fatigue indicators

\begin{tabular}{lccc}
\hline \multirow{2}{*}{$\begin{array}{l}\text { Illumination } \\
\text { intensity, lx }\end{array}$} & Tc, $\mathrm{K}$ & \multicolumn{2}{c}{ Visual fatigue indicator, \% } \\
\cline { 3 - 4 } & & 15.18 & under fluorescent lighting \\
\hline \multirow{2}{*}{200} & \multirow{2}{*}{3000} & 12.17 & 20.39 \\
400 & & 6.45 & 18.27 \\
1000 & & 14.91 & 16.67 \\
200 & \multirow{2}{*}{4000} & 6.40 & 19.23 \\
400 & & 14.21 & 17.14 \\
1000 & & & 9.40 \\
200 & \multirow{2}{*}{5000} & & 18.27 \\
\hline
\end{tabular}

and measurement of the CFFF were taken by means of KPFK-99 “Psychomat”.

Then a one-and-a-half hour long visually intensive proofreading activity with an intellectual element (A-2 category according to SP 52. 13330.2011) was performed. This type of work was considered to be a functional load in the research.

On completion of the work the observers

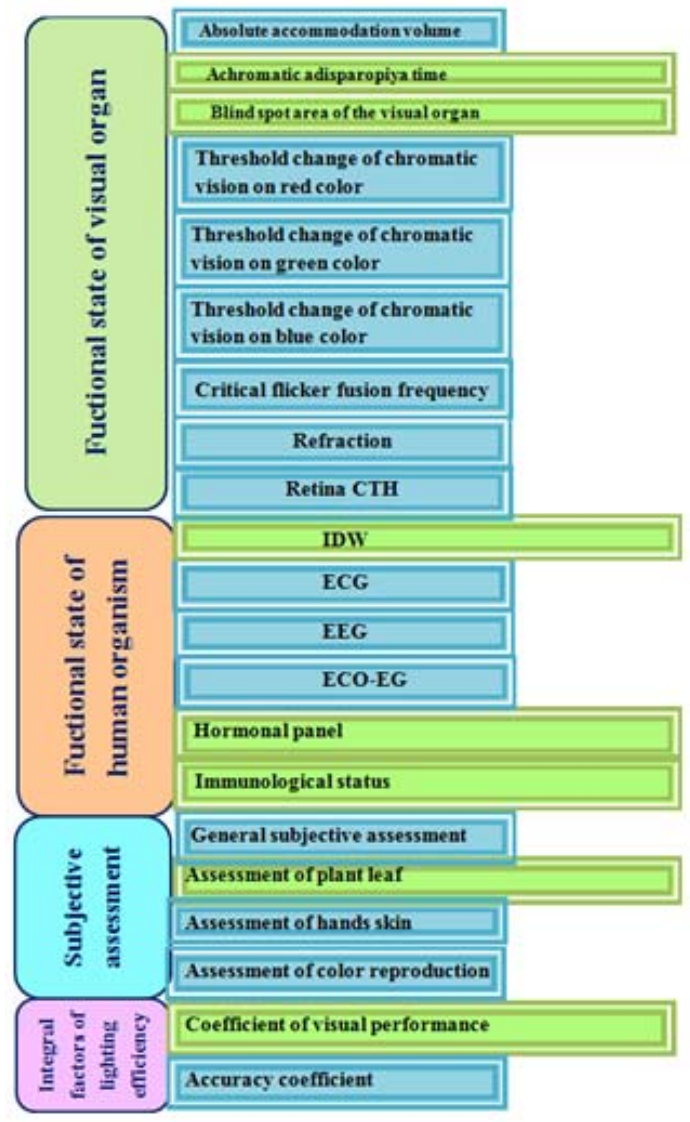

Fig. 1. Psychophysiological "image” of fatigue under LED lighting conditions (Tc = $3000 \mathrm{~K})$ were asked to fill in questionnaires on the lighting variant subjective assessment and a complex of measurements was later performed in the following sequence:

a) work with proof samples;

b) determination of the nearest distinct vision point;

c) measurement of the CFFF;

d) testing for projected blind spot area uniocularly.

Then the observers went back to the first workspace and were repeatedly subject to chromatic vision threshold measurements.

The investigation results were recorded to the special protocols data from which was used for statistical analysis using Statistica 6.0 program and for making conclusions on the lighting conditions efficiency.

\section{DISCUSSION}

\section{Visual functions research}

Studies of the AAE showed that its values decrease in the course of strenuous work under every lighting condition variant concerned (Tables $1,2)$.

The results of determining of the AAE change significance after visual workload according to the Student's t-test allowed to acknowledge that significant changes in the state of AAE ( $<0.05)$ nevertheless not exceeding the boundaries of natural variations for this indicator ( 0.5 - 1.5 diopter) were observed nearly in all lighting variants.

Influence of the light environment spectral structure on the studied change of accommodation indicator at the fixed illumination intensity level according to the Student's t-test 
was found for the compared variants at Tc $4000 \mathrm{~K}$ for every illumination intensity level and at Tc 5000 $\mathrm{K}$ for 200 and $400 \mathrm{~lx}$.

The highest AAE value both prior to work start and after its completion was recorded under LED lighting conditions. The value of AAE after the work completion under LED lighting conditions exceeded the basic variant value by $0.6-0.7$ diopter $(6.3-8.4 \%)$ at Tc $4000 \mathrm{~K}$ within the illumination intensity range from 200 to 1000 lx; 0.5 - 0.7 diopter $(6.0-8.0 \%)$ at Tc $5000 \mathrm{~K}$ within the illumination intensity range from 200 to $400 \mathrm{~lx}$. Thus, it was ascertained that

a) $\mathrm{AAE}$ value decrease in the course of work, determined primarily by the type of visual tasks, is of local nature and deals with reversible processes in the visual organ; by the start of the next day the indicators of AAE come to the initial values;

b) the visual organ accommodates better under LED lighting which could be explained by the higher ciliary muscle activity and is obviously connected with biological necessity in the LEDs radiation spectrum.

In the course of the experimental investigations it was discovered that the higher visual fatigue leads to the lower achromatic asthenopia (AA) time threshold which is used to determine the eye muscles state. Significance of the achromatic asthenopia time threshold change due to visual activity was found out in all of the lighting variants $(p<0.05)$. The research results of achromatic asthenopia time threshold are given in Tables $4-5$.

Influence of illumination intensity level on the achromatic asthenopia time change during the one-and-a-half hour long visually intensive activity was proved by means of [hy ${ }^{2}$ test with high significance values nearly under all lighting variants, although the correlation value is small (Table 6).

Influence of the radiation spectral structure under the fixed illumination intensity conditions on the achromatic asthenopia time change is characterized by a high degree of relevance. In all compared variants change significance according to the Student's t-test has $\mathrm{p}<0.05$.

The achromatic asthenopia time both prior to the work start and after its completion had longer duration under LED lighting conditions. This evidences favorable effect of LED lighting on the muscle function of the visual analyzer: usual muscle tone was achieved with the reduced muscle efforts. Therefore LED lighting ensures better working conditions for the accommodativemuscular system of the visual organ.

In the course of study of the projected blind spot area it was ascertained that the retinal fatigue evaluated by the peripheral vision state led to the positive increase of the physiological blind spot area after completion of intensive visual activity. The range of increase as compared with the initial value for LL lighting variants made 6.57 $-12.06 \%$; for LED lighting variants $-3.87-10.77$ $\%$. It was determined that in the course of visual workload at Tc $3000 \mathrm{~K}$ LED lighting facilitates lower visual fatigue as compared with luminescent lighting ( $\mathrm{p}<0.05)$. For the variants with Tc $5000 \mathrm{~K}$ the differences between LED and luminescent lighting as related to the studied indicator were not significant $(\mathrm{p}>0.05)$.

In the course of study of the chromatic vision acuity there was detected an uneven pattern of change of the chromatic thresholds depending on different lighting variants. Analysis of the obtained results demonstrates that during visual activity under luminescent and LED lighting the retina state was not similar which was obviously connected with photochemical reaction in the retina which may slow down or become more intensive under action of radiation within the different portions of the visible spectrum. However, the spectral distribution influence was detected only in regard to c-receptor of the retina: for radiation with Tc $4000 \mathrm{~K}(1000 \mathrm{~lx})$ and Tc $5000 \mathrm{~K}$ (400 and $1000 \mathrm{~lx}$ ). For the other studied conditions the spectral distribution influence was insignificant which can be explained by the nature of visual tasks - work with achromatic objects not connected with determining of color differences as well as by the qualitative lighting characteristics - favorable radiation spectral distribution, absence of light flux flicker.

Assessment of the state of the visual organ central division was made by means of the critical flicker fusion frequency (CFFF) method. Analysis of the CFFF absolute values as of the time prior to the work start and after its completion didn't allow to determine the most preferable 
radiation structure: the Student's t-test did not confirm significance of the differences within the studied range of illumination intensity and Tc. In other words, the CFFF index under LED lighting conditions is not lower then under LL lighting. The investigation results lead to the inference that LED lighting does not have suppressive effect on the CNS status. The CFFF decrease in the course of experiment is pertaining to the intensive visual activity being performed, this process has a reversible nature - by the start of the next day the indicators of the initial values reestablished.

Based on the results of the conducted research in the reference and primary panels on the $60^{\text {th }}$ experimental day, it was ascertained that in both panels after completion of the experiment the vision acuity of the both eyes remained the same and made 1.0, the refraction was also predominantly emmetropic within the physiological standard limits. Computer-assisted tomography of the retina allowed studying its different values which are given in Tables 7 and 8.

The analysis of the survey data did not confirm reliable differences in studied indicators for the observers both in the reference and primary panels. The foveola profile did not change, the retina architectonics was not affected, the optic disc was of normal size, the disk rim extent and area had no abnormalities; the physiologic excavation extent was normal, the area was not enlarged; correlation of the optic disc excavation area to the optic disc area were within normal limits: for the reference and the primary panels $0.029 \pm$ 0.02 and $0.28 \pm 0.02$ correspondingly; the peripapillary nerve fibers were not damaged. It leads to the conclusion that the observers' retina state did not undergo significant changes and was not harmfully affected during intensive visual activity under both LL and LED lighting conditions.

\section{Visual fatigue research}

Values of the visual fatigue indicator are given in Table 9, data of which evidence decrease of the visual fatigue with increase of the illumination intensity level. As it was found such decrease is not significant at $1000 \mathrm{~lx}$ at any level of Tc both for LL and LED lighting conditions.

It was ascertained that during the oneand-a-half hour long visually intensive activity LED lighting induced lower visual fatigue. Significant influence of the spectral distribution on the visual fatigue indicator was proved for all of the studied lighting variants with $\mathrm{p}<0.05$ according to the Student's t-test. Analysis of the obtained results allowed making the conclusion that the light environment created by means of LEDs enabled to ensure the lower visual fatigue and correspondingly the higher visual performance as compared to LL. LED lighting may be considered as more favorable from the point of view of hygiene during intensive visual activity by contrast to the basic lighting variant. In accordance with the results of analysis of the visual functions dynamics as well as of other indicators describing the body functional state (Amelkina S.A. et al., 2014) we have composed a psychophysiological "image" of fatigue under LED lighting conditions, example of which is given on Figure 1 for the illumination intensity of $400 \mathrm{~lx}$ and Tc $3000 \mathrm{~K}$. As it appears from the Figure, only 9 among 21 studied indicators had the significant preference towards LED lighting conditions, the other 12 had dynamics corresponding to LL lighting conditions. For Tc $4000 \mathrm{~K}$ there was determined significant preference for 7 indicators and for Tc $5000 \mathrm{~K}$ - for 8 indicators.

\section{CONCLUSION}

In the course of the experimental investigations it was ascertained that LED lighting does not entail harmful effect on the visual organ and the human body as a whole. The reported changes in the studied functional indicators of the visual organ in the course of visual activity are within the set boundaries of the physiological variations and have a reversible nature.

The elaborated comprehensive methodology for psychophysiological and hygienic evaluation of the LED lighting conditions effect on the status of the visual organ and the human body as a whole may be used both for investigation of LEDs or any other LSs lighting conditions and for studying the lighting effects on various age and gender groups. The undertaken research efforts allows elaborating the scientifically based recommendations for use of LED light luminaires (with due account for the spectral distribution) in the public and administrative, accommodation and production premises. Use of LED LSs creates opportunities for the visual activity efficiency increase under 
the studied lighting conditions at time of intensive visual works performance (up to $15 \%$ ). The material obtained in the experimental investigations may be taken into account during designing of the lighting equipment with LED light luminaires aimed both for newly constructed buildings and for remodeling of the existing lighting systems. In this case replacement of LL lighting fixtures by LED ones will ensure significant decrease of the extent of electric power consumed for lighting purposes.

\section{ACKNOWLEDGEMENTS}

The research was carried out with the financial support of the Ministry of Education and Science of the Russian Federation in the context of the government assignment basic part for the project: "Realization of theoretical and experimental research aimed at the development of promising energy saving LED optical emission sources and efficiency assessment of lighting installations built on their base".

The authors express their gratitude to $\mathrm{PhD}$ in Medicine Doctor Aksenova S. V. and PhD in Medicine Kulikova M.P. for the assistance in organization and carrying out of the investigations.

\section{REFERENCES}

1. Aladov, A.V., Vasilieva, E.D., Zakgeim, A.L., Itkinson, G.V., Lundin, V.V., Mizerov, M.N., Ustinov, V.M. and Tsatsulnikov, A.F., On modern powerful LEDs and their light engineering appliance. Light\&Engineering. 2010; 3: 8 -16.

2. Aladov, A.V., Zakgeim, A.L., Mizerov, M.N., Chernyakov, A.E., Concerning biological equivalent of radiation of lightemitting diode and lamp light sources with correlated colour temperature from $1800 \mathrm{~K}$ up to $10000 \mathrm{~K}$. Light\&Engineering, 2012; 3: 9-14.

3. Amelkina, S. A., Zheleznikova, O.E., Kiryukhina, S.V. and Sinitsyna, L.V., Developing a complex methodology for influence evaluation of LED lighting on the visual organ and the human body as a whole. Natural and technical sciences. 2013; 5(67): 249-257.

4. Amelkina, S. A., Zheleznikova, O. E. and Sinitsyna, L. V., Revisiting Practical Guidelines for use of Light-Emitting Diodes for Lighting of Public and Administrative Buildings. Research Journal of Pharmaceutical, Biological and
Chemical Sciences, September - October. 2014; 5(5): 1707-1711.

5. Behar-Cohen, F., Martinsons, C., Vienot, F. and Zissis, G. Light-emitting diodes (LED) for domestic lighting: Any risks for the eye? Progress in Retinal and Eye Research. 2011; 30: 239-257. http://dx.doi.org/10.1016/ j.preteyeres.2011.04.002.

6. Bizjak, G., Klanickek-Gunde, M., Kobau, M.B. and Malovr-Rebek, K., Emitted spectra and photobiological action of LEDs. Light \& Engineering. 2013; 2: 20-23.

7. Borovkov, S.A. Philips Lighting experience in LED use for illumination of buildings for different purposes. Light\&Engineering. 3: 18-22.

8. Düe, D., LED lighting: favourable opportunities or health risks. Light\&Engineering. 2012; 4: 2325.

9. $\quad$ Eliseyev, N.P., Reshenov, S.P. On peak light and color performance of white LEDs. Light \& Engineering. 12: 12 -18.

10. Hirayama, H., Recent progress and future prospects of AlGaN-based high-efficiency deepultraviolet light-emitting diodes. Japanese Journal of Applied Physics, 2014; 53: 10. doi:10.7567/JJAP.53.100209.

11. Kawasaki, S., Horikoshi, Y., Yainazaki, A., Kasahara, K., Impact of two competing energy transfer mechanisms on spectra in organic light emitting diodes. Conference on Optics for Solar Energy (SOLAR) at the Renewable Energy and the Environment Congress, Eindhoven. 2012; 64-65. Washington (D.C.). • doi:10.1364/ E2.2012.JM5A.24.

12. Kuchma, V.P., Teksheva, L.M., Suhareva, L.M. Hygienic basics of LED use in artificial lighting facilities. M.: "Scientific children's health center" of Russian Academy of Medical Sciences (monograph). 2013; 248.

13. Radomsky, N. V., The Russian LED production market review, 2012. http://www.aenergy.ru/ 4087ý.

14. Sliney, D. H., Influence of new lighting devices on people's health and safety. Light \& Engineering. 2010; 3: 49-50.

15. SP 52.13330.2011 Natural and artificial lighting URL: http://docs.cntd.ru/document/ 1200084092. Application date: 14.04.2014.

16. Teksheva, L. M., A comparative hygienic assessment of lighting conditions provided with luminescent lamps and LED light sources in schools. Light \& Engineering, 2012; 5: 16-22.

17. Wittig, N., A Small Light Source with Great Potential: The Future of Leds - Already Promoted by Zhaga. Light\&Engineering, 2012; 4: 19-26). 
18. Wright, M., Debate continues over the impact of light on human health. LEDs magazine. 2010; 46: 25.

19. Zak, P.P., Ostrovsky, M.A., LED lighting potential risks for children's and teenagers' eyes.
Light\&Engineering. 2012; 3: 4-6.

20. Zakgeim, A.L., LED lighting systems: energy efficiency, visual perception, health safety. Light \& Engineering. 2012; 6: 12-21). Light \& Engineering, (\# 5, p. 16-22) 